\title{
MRI-Evaluation of Suprascapular Notch Morphometry and Its Clinical Applications
}

\section{Thaer M. Farhan ${ }^{1 *}$, Huda Rashid Kamoona ${ }^{2}$}

${ }^{1}$ Associate Professor of Clinical Anatomy and Embryology, Department of Human Anatomy, College of Medicine, Al-Nahrain University, Baghdad, Iraq

${ }^{2}$ Assistant Professor of Human Anatomy, Department of Human Anatomy, College of Medicine, Al-Nahrain University, Baghdad, Iraq

Correspondence to: Thaer M. Farhan, Associate Professor of Clinical Anatomy and Embryology, Department of Human Anatomy, College of Medicine, Al-Nahrain University, Baghdad, Iraq

Received date: January 16, 2021; Accepted date: January 29, 2021; Published date: February 5, 2021

Citation: Farhan TM, Kamoona HR (2021) MRI-Evaluation of Suprascapular Notch Morphometry and Its Clinical Applications. J Med Res Surg 2(1): pp. 1-6. Copyright: (C2021 Farhan TM, et al. This is an open-access article distributed under the terms of the Creative Commons Attribution License, which permits unrestricted use, distribution and reproduction in any medium, provided the original author and source are credited.

\section{ABSTRACT}

The suprascapular notch, a depression on the lateral part of the superior border of the scapula, medial to the coracoid process, is covered by the superior transverse scapular ligament, which is converted into a foramen. Sometimes it might be ossified forming a complete osseous foramen. The Suprascapular Notch (SN) served as a passage for the Suprascapular Nerve (SSN). Study the morphology of the suprascapular notch and the suprascapular transverse ligament based on MRI, variations in shape and dimensions of the suprascapular notch. A group of 100 patients underwent MRI examination of the scapular region through the period from $10^{\text {th }} \mathrm{July} 2019$ to $15^{\text {th }}$ Feb 2020. Different morphological types of the suprascapular notch were encountered in the study, the most common type was type III, while type I was less common in the study. The symmetry of the morphological feature of SN bilaterally was seen in $51 \%$ of the cases. Conclusively, the symmetry of the suprascapular notch is not a constant feature bilaterally.

\section{Keywords:}

Suprascapular notch, Suprascapular nerve, Scapula, Shoulder pain, Shoulder MRI, Suprascapular nerve entrapment

\section{Introduction}

The suprascapular notch, a depression on the lateral part of the superior border of the scapula, medial to the coracoid process, is covered by the superior transverse scapular ligament, which is converted into a foramen. Sometimes it might be ossified forming a complete osseous foramen. The Suprascapular Notch (SN) serves as a passage for the Suprascapular Nerve (SSN) [13].

The Superior Transverse Scapular Ligament (STSL) forms the roof of the suprascapular notch, which is the most common location of entrapment of the suprascapular nerve, a cause of

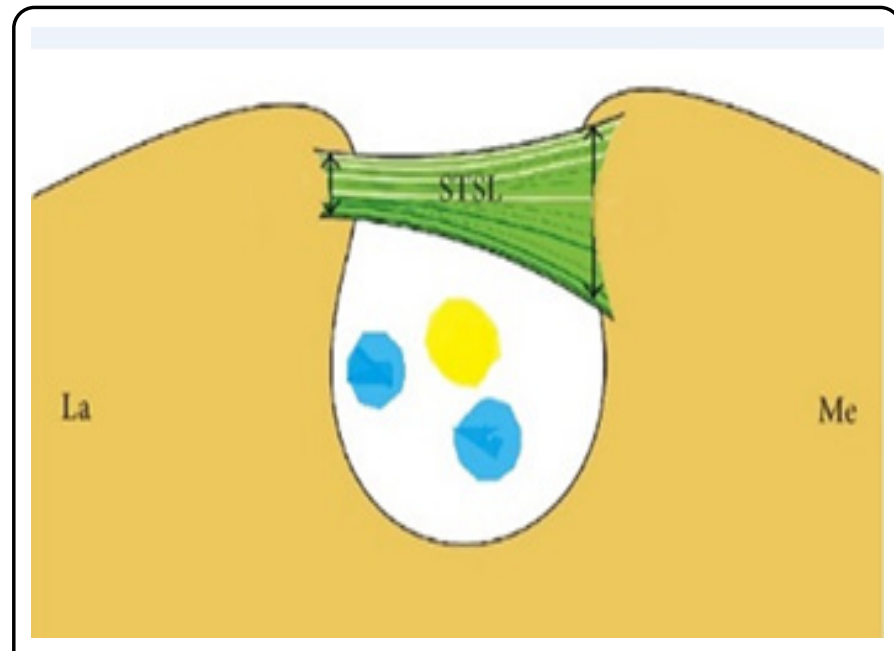

Figure 1: Suprascapular notch closed by suprascapular ligament, the suprascapular nerve and veins pass below the ligament. shoulder pain and weakness $[3,4]$ (Figure 1). The first description of suprascapular nerve entrapment syndrome at the site of the suprascapular notch was made by Kopell and Thompson $[5,6]$. The shape and size of the Suprascapular Notch (SN) are one of the most important risk factors in suprascapular nerve entrapment $[7,8]$.

The Superior Transverse Scapular Ligament (STSL) is a fibrous band connecting two borders of Suprascapular Notch (SN) on the upper border of the scapula. The Suprascapular Nerve (SSN) passes below the ligament through the opening while the suprascapular artery crosses over the ligament $[2,9,10]$. Evaluation of the morphology of the suprascapular notch region is important from a clinical point of view because it is the most common site of suprascapular nerve compression and injury. The suprascapular notch is characterized by variable morphology. However, its development is not well studied [11,12].

Anatomical variations and the anomalous or ossified superior transverse scapular ligament are also considered to be risk factors for suprascapular neuropathy [13]. The shape and morphology of the suprascapular notch is the most critical point that affects the etiology of nerve neuropathy like neuropraxia, for instance. the suprascapular notch was classified according to a fivefold classification (Type I, deeper than wider; Type II, equally deep and wide; type III, wider than deeper; type IV, bony foramen; type $\mathrm{V}$, discreet notch $[14,15]$.

\section{Objectives:}

- $\quad$ Study the morphology of the suprascapular notch based on $\mathrm{MRI}$, variations in shape and dimensions of suprascapular notch

- Study the frequency of visualization of the superior transverse scapular ligament, describe its typical MRI appearance 


\section{Materials and Methods}

A group of 100 patients underwent MRI examination of the scapular region through the period from $10^{\text {th }}$ July 2019 to $15^{\text {th }}$ February 2020. These 100 clinical cases were referred to the radiology department due to different medical complaints. The study is a retrospective type including already performed MRI examination of the shoulder region which renders the suprascapular region more feasible to be visualized and evaluated.

The inclusion criteria were as follows: both scapulae encompassed in a field of view; no artifacts; no pathologies concerning the scapulae. Based on visual assessment and measurements. No fractures or direct trauma of the scapula.

Measurements of the suprascapular notch and superior
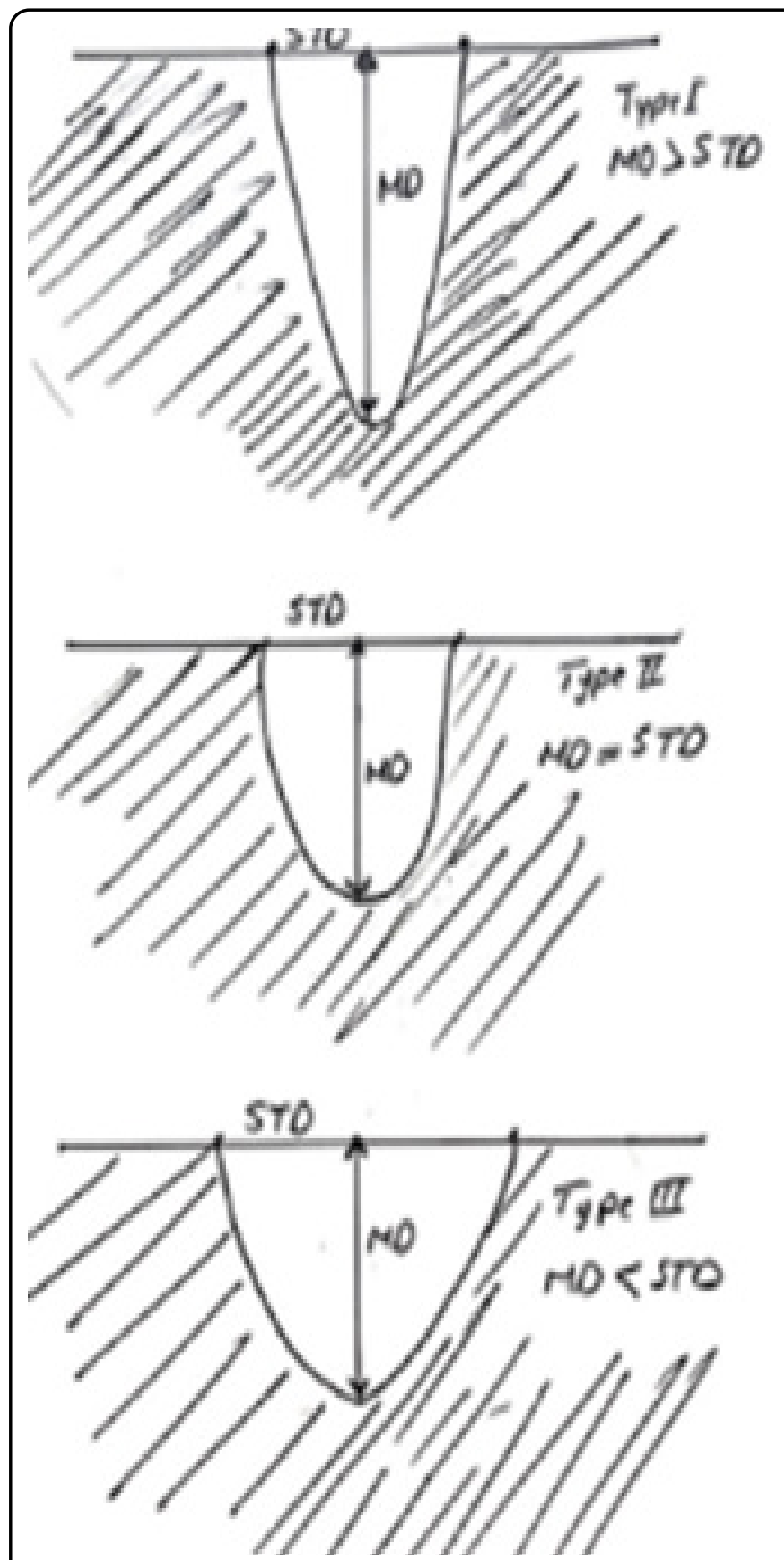

Figure 2: Types of the SN; Suprascapular Notch (SN), A: Shows type I; B: Shows type II; C: Shows type III. transverse scapular bar were taken with the help of digital scales and radiographic markers that are built in the MRI software system. The following suprascapular notch dimensions were measured: maximal depth, superior transverse diameter and middle transverse diameter were recorded. The data was analyzed statistically.

1. Superior Transverse Diameter (STD): the length of the line between two corners of the SN.

2. Maximal Depth $(M D)$ : the length of the vertical line from the imaginary line between two corners of the SN to the deepest point of the notch.

According to the above-mentioned dimensions, the $\mathrm{SN}$ is categorized into the following types based on their morphology and measurements:

Type I: MD dimension is longer than STD (Deeper notch)

Type II: MD and STD are equal

Type III: STD is longer than MD (Wider notch)

Type IV: Osseous foramen by a bony bridge

Type V: Discrete (Shallow) notch, Figure 2 (Illustration of SN types)

\section{Results}

The current study is characterized by simple and informative data that can be interpreted radiologically and anatomically. These data can be explained simply as follows:

The total number of the examined patients by MRI technique was 100 patients, a total number of 200 scapular bones were studied by MRI bilaterally and retrospectively then were analyzed to classify suprascapular notches into five types. The following important data were recognized from the study

- Male: female distribution for the total number of patients was 59:41

- The symmetry of the morphological feature of SN bilaterally was recognized in 51 cases out of 100 patients.

- $\quad$ Figure 3

- Male to female ratio of the symmetry cases was 23:28

- Symmetry was more frequently seen in females $(54.90 \%$ versus $45.10 \%$ in male) with no significant difference $(P=0.8413)$

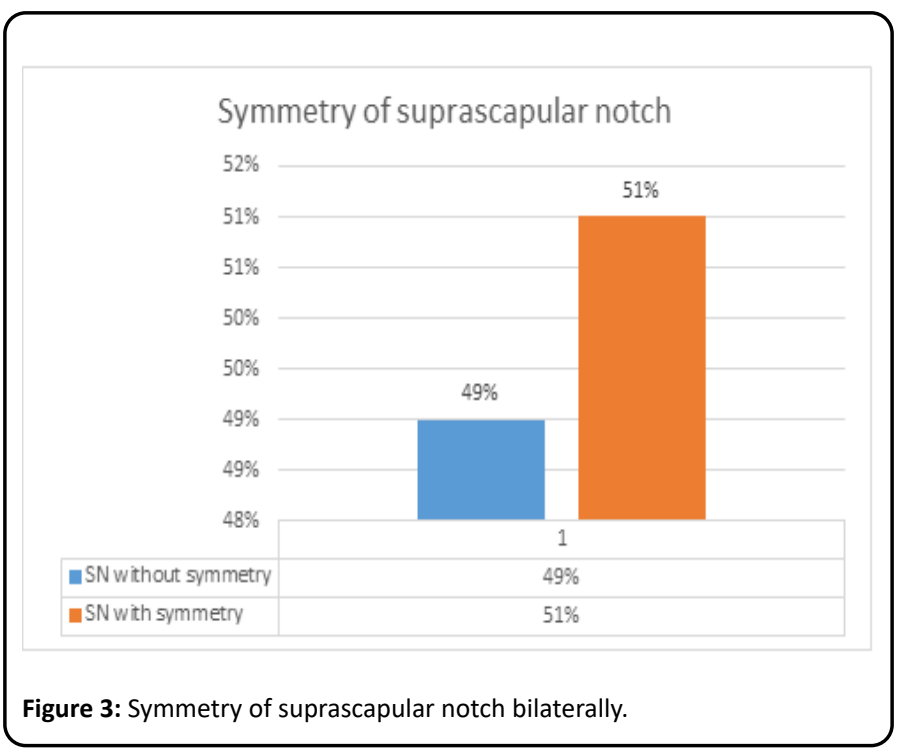




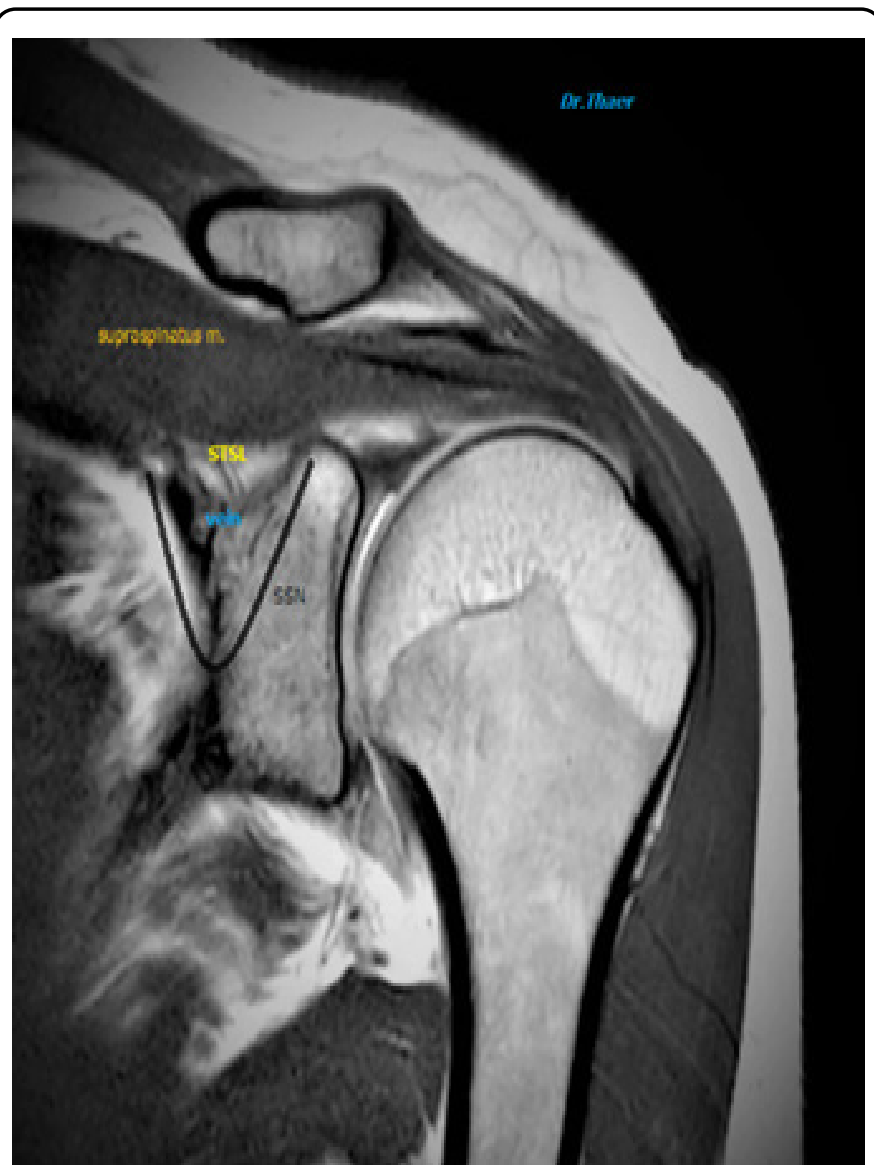

Figure 4: MRI image shows deep Suprascapular Notch (SN), shows deep notch MD more than STD.

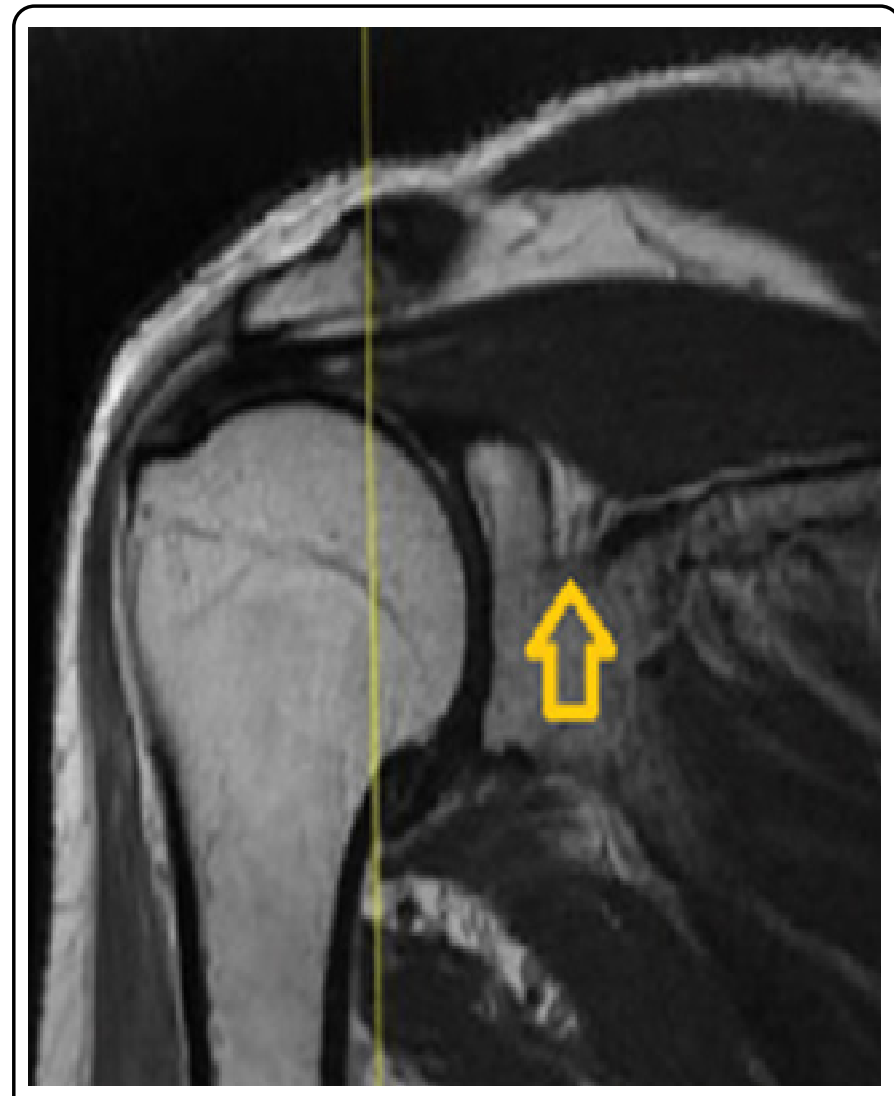

Figure 5: MRI image shows suprascapular notch with MD dimension=STD.

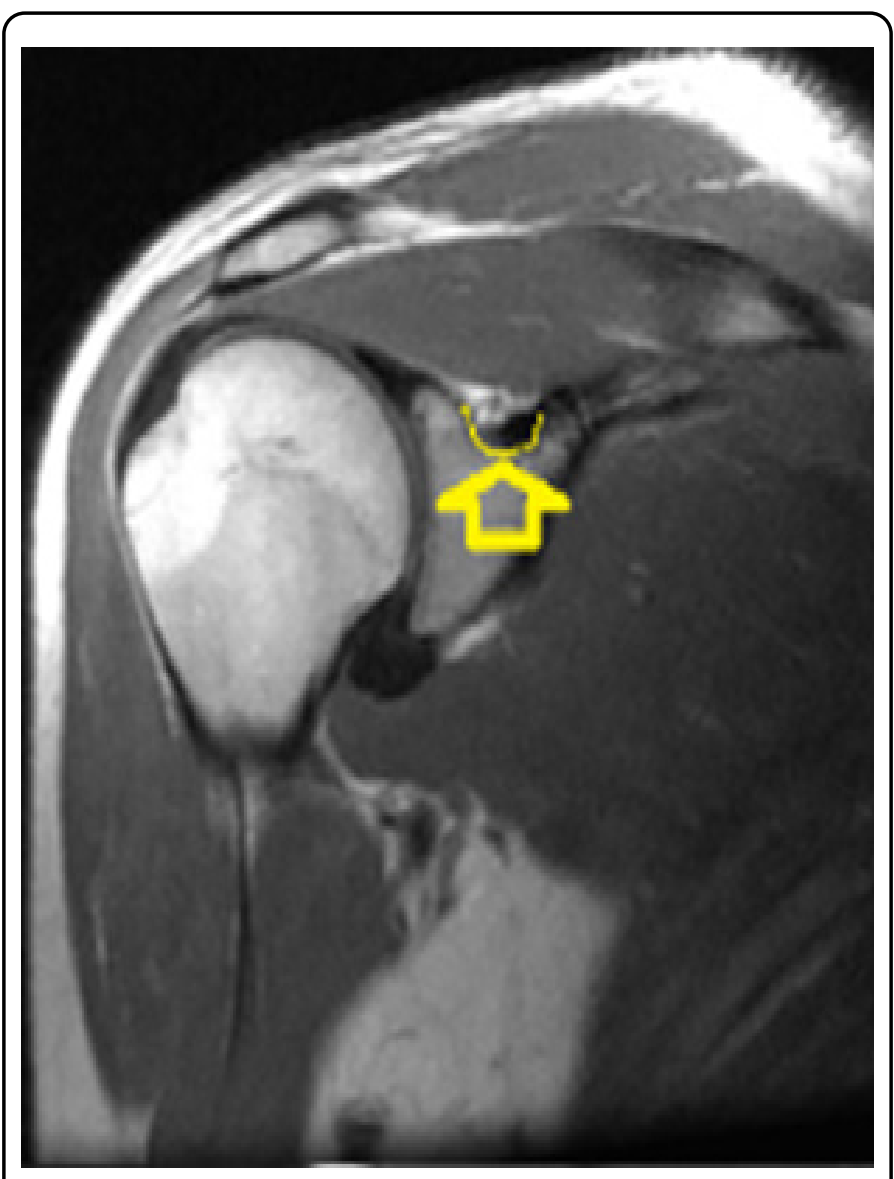

Figure 6: MRI image shows wider suprascapular notch (STD more than MD).

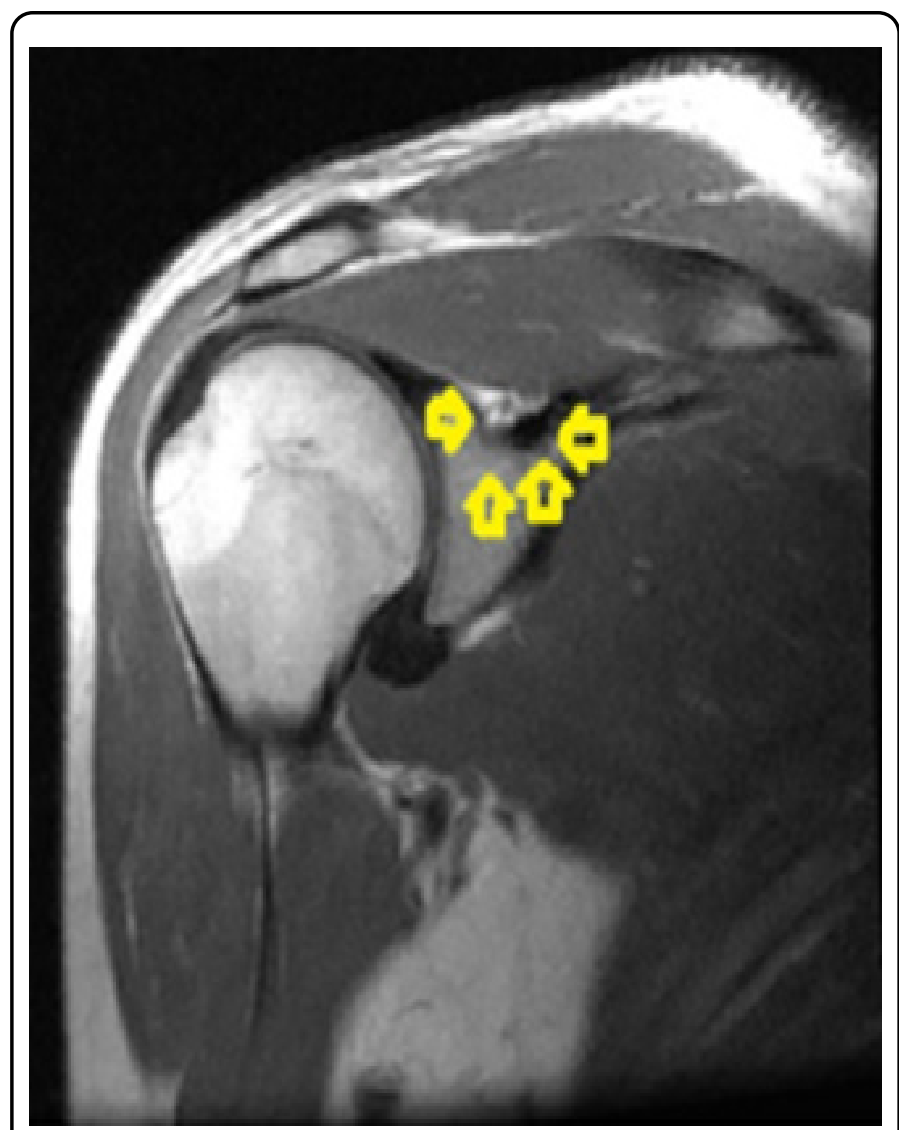

Figure 7: MRI image shows discrete suprascapular notch (Shallow notch). 
Regarding the morphology of the suprascapular notch; SN, the following percentage of occurrence were encountered in the study:

Type I: MD dimension is longer than STD, seen in 48 out of 200 scapulae (Figure 4).

Type II: MD and STD are equal, seen in 4 out of 200 scapulae (Figure 5).
Type III: STD is longer than MD, seen in 112 out of 200 scapulae (Figure 6).

Type IV: Osseous foramen by a bony bridge, seen in 10 out of 200 scapulae.

Type V: Discrete (Shallow) notch, seen in 26 out of 200 scapulae (Figure 7).

Table (1) for more explanations:

Table 1: The frequency of SN in the examined scapular bones by MRI, according to types and symmetry bilaterally.

\begin{tabular}{|l|l|l|l|l|}
\hline SN type & $\begin{array}{l}\text { No. of cases /200 } \\
\text { scapulae }\end{array}$ & $\begin{array}{l}\text { Percentage \% from } \\
\mathbf{2 0 0} \text { scapulae }\end{array}$ & $\begin{array}{l}\text { No. of cases have } \\
\text { symmetry bilaterally } \\
\text { per } \mathbf{1 0 0} \text { patients }\end{array}$ & $\begin{array}{l}\text { Percentage \% of } \\
\text { symmetry cases (51) }\end{array}$ \\
\hline Type I & $48 / 200$ & $24 \%$ & $8 / 100$ & $17 \%$ \\
\hline Type II & $4 / 200$ & $2 \%$ & $1 / 100$ & $2 \%$ \\
\hline Type III & $112 / 200$ & $56 \%$ & $33 / 100$ & $64 \%$ \\
\hline Type IV & $10 / 200$ & $5 \%$ & $2 / 100$ & $2 \%$ \\
\hline Type V & $26 / 200$ & $13 \%$ & $7 / 100$ & $15 \%$ \\
\hline Total & $200 / 200$ & $100 \%$ & $51 / 100$ & $100 \%$ \\
\hline
\end{tabular}

Regarding the superior transverse scapular ligament and categorization according to its structure. In the current study, the best way to visualize the superior transverse scapular ligament, STSL; by using the MRI imaging technique with sagittal plane T1-weighted sequence, the STSL was found to be either

- Visualized in $96 \%$ of the total number of scapular bones examined (192/200) (Figure 8).

- Seen as connective tissue band (fibrous band) in $90 \%$

- An ossified superior transverse scapular ligament render the SSN into bony foramen that is visualized in approximately $6 \%$

- Not visualized in $4 \%$ of the total No. examined $(8 / 200)$

- Was observed more often in male

- Observed in the right scapula more than left one

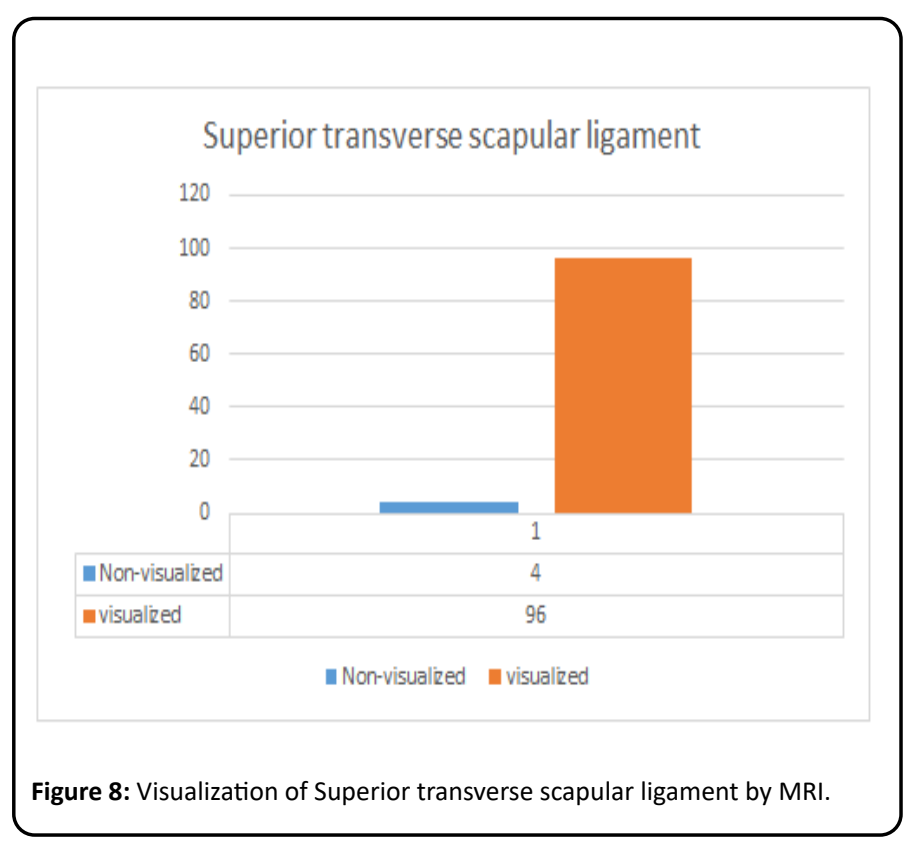

Table 2 for Superior Transverse Scapular Ligament (STSL), categorization according to its type and its frequency.
Table 2: Categorizations and forms of suprascapular ligament found in the current study. to types and symmetry bilaterally.

\begin{tabular}{|l|l|l|}
\hline STSL type & No. of cases & Percentage \% \\
\hline Fibrous band & 180 & 0.9 \\
\hline Ossified band & 12 & 0.06 \\
\hline Non-visualized (absent) & 8 & 0.04 \\
\hline Total & 200 & 1 \\
\hline
\end{tabular}

\section{Discussion}

The shoulder as well the scapular regions pain and dyskinesia is one of the common rheumatological complaints when its etiology is not yet fully described and understood; thus, many clinical studies were carried on to elaborate on this problem [16].

The most evident outcome from the current research was the symmetry of the suprascapular notches bilaterally. According to the study analysis, the SN symmetry is not a constant feature to be considered although, only a little more than half of the cases encountered were found to have the same features bilaterally [3].

According to Dunkelgrun et al, the shape and size of the SN are the most crucial factor in the etiology of the suprascapular nerve entrapment [17]. It could be supposed that humans with longer scapulae have deeper and narrow notches that may predispose to suprascapular nerve irritation and neuropathy. It may be also suggested that scapulae with a wider superior border have a shallower suprascapular notch $[3,18,19]$.

The suprascapular nerve is one of the important structures that might be jeopardized and compressed either by muscular action or vascular effects of the nearby vessels or even a narrow suprascapular notch. The anatomical variations in the shape of the suprascapular notch, and its transformation into a foramen by complete or partial ossification of the superior transverse scapular ligament, are well-known reasons of suprascapular nerve entrapment. [20,21].

The suprascapular nerve may be compressed anywhere along 
its course to the site of innervation, most commonly at SN, the variations in morphometric dimensions of the notch, play a crucial role in suprascapular nerve entrapment [22].

Suprascapular nerve pathology is a rare diagnosis that is increasingly gaining popularity among the conditions that cause shoulder pain and dysfunction. The suprascapular notch is the common site for the entrapment of the suprascapular nerve. Suprascapular nerve compression usually presents with vague pain across the scapula or dull shoulder ache $[23,24]$.

Several other anatomical variations in the region of suprascapular notch like thickened or multiband or even ossified suprascapular ligament should be taken in consideration when elaborate on the causes of suprascapular nerve entrapment [25]. In the cases where the suprascapular ligament is thick or even more evident, we can hypothesize that hypertrophy of the transverse scapular ligament creates a venous obstruction resulting in varicosities of the suprascapular vein which runs with the nerve under the ligament and causes a suprascapular neuropathy. As the suprascapular artery is the most easily recognized structure in the area, it may serve as a useful landmark of the suprascapular notch $[8,26]$. One of the limitations of the current study that the data were collected retrospectively.

\section{Conclusion}

Different morphological patterns of the suprascapular notches have been encountered in the study, the most common type was type III when the STD is larger than MD (Wider notch). The symmetry of the suprascapular notch is not a constant feature bilaterally. The data suggest that the entrapment syndrome is more likely to be associated with a Type I notch because of its specific features.

The STSL can be visualized on the majority of shoulder MRIs and is best seen on sagittal T1-weighted images on our imaging protocol. Evaluation of the STSL can potentially help in identifying pathologic conditions affecting the suprascapular nerve.

\section{Acknowledgment}

We, the authors, greatly thankful for those workers at the Department of Radiology, Al-Imamain Teaching Hospital. It would not have been possible without the exceptional support of them.

\section{Conflict of interest}

The authors declare that there is no conflict of interest in the current work.

\section{References}

1. Kannan U, Kannan NS, Anbalagan J,et al. (2014) Morphometric study of suprascapular notch in Indian dry scapulae with specific reference to the incidence of completely ossified superior transverse scapular ligament. J Clin Diagn Res 8(3): pp. 7-10.

2. Williams PL, Bannister LH, Bery MM, et al. (1995) Gray's anatomy 38th edition. Edinburgh: Churchill Livingstone.

3. Polguj M, Sibiński M, Grzegorzewski A, et al. (2014) Suprascapular Notch asymmetry: A study on 311 patients. Biomed Res Int 2014: 196896.

4. Simeone FJ, Bredella MA, Chang CY, et al. (2015) MRI appearance of the superior transverse scapular ligament.
Skeletal Radiol 44(11): pp. 1663-1669.

5. Kopell HP, Thompson WA (1959) Pain and the frozen shoulder. Surg Gynecol Obstet 109(4): pp. 92-96.

6. Polguj M, Sibiński M, Grzegorzewski A, et al. (2013) Variation in morphology of suprascapular notch as a factor of suprascapular nerve entrapment. International Orthopaedics 37(11) pp. 21852192.

7. Albino P, Carbone S, Candela V, et al. (2013) Morphometry of the suprascapular notch: correlation with scapular dimensions and clinical relevance. BMC Musculoskeletal Disorders 14(1): pp. 172.

8. Jezierski H, Podgórski M, Stefańczyk L,et al. (2017) The Influence of Suprascapular Notch Shape on the Visualization of Structures in the Suprascapular Notch Region: Studies Based on a New Four-Stage Ultrasonographic Protocol, BioMed Res Int 2017: 5323628.

9. Gosk J, Urban M, Rutowski R (2007) Entrapment of the suprascapular nerve: anatomy, etiology, diagnosis, treatment. Ortop Traumatol Rehabil 9(1): pp. 68-74.

10. Singh R (2018) Variations in the origin and course of the suprascapular artery: case report and literature review. Jornal vascular brasileiro 7(1): pp. 61-65.

11. Jezierski H, Podgórski M, Stefańczyk L, et al. (2017) The Influence of Suprascapular Notch Shape on the Visualization of Structures in the Suprascapular Notch Region: Studies Based on a New Four-Stage Ultra Sonographic Protocol. Biomed Res Int 2017: 5323628.

12. Agrawal D, Singh B, Dixit SG, et al. (2015) Morphometry and variations of the human suprascapular notch. Morphologie 99(327): pp. 132-40.

13. Natsis K, Totlis T, Tsikaras P, et al. (2007) Proposal for classification of the suprascapular notch: A study on 423 dried scapulas. Clin Anat 20(2): pp. 135-139.

14. Polguj M, Sibiński M, Grzegorzewski A, et al. (2014) Morphological and radiological study of ossified superior transverse scapular ligament as potential risk factor of suprascapular nerve entrapment. Biomed Res Int 2014: 613601.

15. Podgórski M, Polguj M, Topol M, et al. (2018) Suprascapular notch morphology in the pediatric population: a computed tomography study. Anat Sci Int 93(1): pp. 42-47.

16. Panagiotopoulos AC, Crowther IM (2019) Scapular Dyskinesia, the forgotten culprit of shoulder pain and how to rehabilitate. SICOT-J 5: pp. 29.

17. Dunkelgrun M, lesaka K, Park SS, et al. (2003) Interobserver reliability and intraobserver reproducibility in suprascapular notch typing. Bull Hosp Jt Dis 61(3-4): pp. 118-122.

18. Fritz RC, Helms CA, Steinbach LS, et al. (1992) Suprascapular nerve entrapment: evaluation with $M R$ imaging. Radiology 182(2): pp. 437-444.

19. Polguj M, Majos A, Waszczykowski M, et al. (2016) A computed tomography study on the correlation between the morphometry of the suprascapular notch and anthropometric measurements of the scapula. Folia Morphologica (Warsz):75(1): pp. 87-92.

20. Gupta C, Palimar V, Akshay BM, et al. (2016) Morphometric study of suprascapular notch and scapular dimensions with 
their clinical implications. Res J Pharm Biol Chem Sci 7(5): pp. 2105-2112.

21. Polguj M, Jędrzejewski KS, Podgórski M, et al. (2011) Correlation between morphometry of the suprascapular notch and anthropometric measurements of the scapula. Folia Morphologica 70(2): pp. 109-115.

22. Khurshid N, Kaur M (2019) Suprascapular notch and its anatomical variants. Int J Scient Res 8(8): pp. 7-8.
23. Kostretzis L, Theodoroudis I, Boutsiadis A, et al. (2017) Suprascapular Nerve Pathology: A Review of the Literature. Open Orthop J 28(11): pp. 140-153.

24. Sangam MR, Devi SS (2014) Morphometry of Suprascapular Notch and its Correlation with that of Scapula. J Clin Diagn Res 8(4): pp. 1-2.

25. Tubbs RS, Nechtman C, D’Antoni AV, et al. (2013) Ossification of the suprascapular ligament: A risk factor for suprascapular nerve compression. Int J Shoulder Surg 7(1): pp. 19-22. 